albumen required to make flesh with this beef-tea and which the blood must have to supply would amount to 149 grains ( 9.64 grammes). Now, twenty pounds of blood would contain (at 90 per 1000) 12,600 grains of albumen; so that blood may be expected to be able to continue supplying albumen to the material of beef-tea to make flesh some time after any food has been taken. This length of time must be regulated by the rate of the formation of urea and that of the waste of tissues.

\section{A CASE OF FEIGNED DISEASE.*}

\section{By ANDREW AITCHISON, M.B., Wallsend.}

THE history of this case is somewhat obscure ; but I shall give it as nearly as I can remember, having heard it from the female who was the subject of disease. The case is rather interesting, as the woman lay in bed for twenty-two years, never being up during that period even to have her bed made. She also vomited for seventeen years matter having a frecal character.

J. H., aged 19 at the time of attack, was seized with a fit in the summer of 1850 while making hay, which the medical man who was called pronounced to be hysterical. From this time, she never was strong. About six months after this fit, she was attacked with an inflammation of the chest, which left her very weak. On recovering from this attack, she attended the Newcastle Infirmary regularly for some time, as she still suffered from hysterical fits; but, as she did not receive any benefit from the medicines she took, and seemed to grow weaker, her medical adviser recommended that she should lie in bed until she was stronger. As she appeared to be no better in bed, she was advised to get up and try to go about again ; but this, she said, she was unable to do, so there she remained. About five years after the commencement of her illness, she was seized one day with vomiting and violent pain in the bowels, and at the time the pain was very severe she thought she felt something give way. The pain left in a few days, but the vomiting continued, and no medicine she took relieved it in the slightest.

She came under my father's care, on the death of the parish surgeon who attended her, in the summer of $\mathbf{1} 862$. She then complained of a tightness over the chest with pain shooting through to the back, and a severe cough, occasionally attended with spitting of blood. There was great tenderness over the abdomen. She vomited several times a day, the vomited matter having a very offensive and frecal odour. Her bowels were moved, she said, about once in five weeks. I may as well mention that at each visit the vomited matter was shown, and it always had the appearance of being newly ejected. The stench, also, was unbearable. On examining the patient, no tumour or anything abnormal was discovered in the abdomen. The chest was dull on both sides, and she had all the signs of incipient phthisis. After having tried various drugs with a view to check the vomiting, and seeing that she got no better, but that the sickness seemed to be aggravated by taking medicine, the conclusion arrived at was that the patient might be suffering from gastro-colic fistula, although the case was entered in the pauper-book as one of doubtful character. During her illness she was seen by several medical men to whom I had mentioned the case. Nearly all had some doubt as to where the vomited matter came from, and two said that they did not believe she vomited at all; but as she had been seen to vomit on several occasions, that doubt was removed.

About two years ago, I asked Dr. Philipson to see her with me. He examined the patient and the vomited matter very carefully, and in the vomited matter he found large quantities of cotton-wool mixed with articles of food, and he then expressed his opinion that the patient swallowed cotton-wool in order to cause the vomiting and the peculiar character of the vomit; and that her object was to deceive, in order to obtain sympathy and charity from her neighbours. On being told that she was accused of eating cotton-wool in order to cause the vomiting, she denied it, and said that she would never give herself so much pain as that caused by the vomiting if she could help it. The symptoms continued without variation for seventeen years; and about three weeks before her death she was seized with obstinate diarrhoea, and the vomiting and sickness suddenly ceased. The diarrhœea lasted for three weeks, when she died as from consumption.

After death, I made a post mortem examination of the body. Great difficulty was experienced in opening the chest, owing to its sternal portion being firmly bound down by the pleura. The pericardium was firmly attached to the pleura and ribs of the left side, and also to the diaphragm. Both lungs were firmly attached to the walls of the chest by old adhesion. Both lungs were infiltrated throughout by tubercle, and in the upper lobe of the left lung there existed a cavity of large size. The pericardium was thickened, and contained about two ounces of serum. The heart was exceedingly small. The abdomen was carefully examined. No communication existed between the stomach and colon. The stomach itself was healthy, and of normal size. The liver was enlarged and slightly fatty. The bowels appeared to be healthy throughout, with the exception of a little redness of the mucous membrane. The uterus with its appendages and all the other organs were perfectly healthy. It was very satisfactory after so many years of doubt to find out the true nature of the case. Instead of its turning out to be one of gastro-colic fistula as it had been supposed to be for many years, it was found to be one of hysteria, as revealed by the post mortem examination. It is also very remarkable that she should have deceived her friends so long; even her own mother, who waited on her day and night, seemed to be perfectly ignorant of her deception.

\section{ADDISON'S DISEASE.}

\section{BY JOHN F. NICHOLSON, F.R.C.S., Stratford.}

A. W., aged I4, was seized on September 14 th, I87 I, with vomiting of food and bile. His bowels had been freely moved by effervescing magnesia the day before. His illness could not be traced to any cause except having eaten some ripe red plums. Diarrhœa was epidemic. The vomiting continued more than a week, in spite of the most careful diet and medical care. Turpentine stupes were applied, and ice was freely given. Beef-tea was the first thing retained ; brandy and water was most unpalatable. I had ordered it, as his pulse was very low and the exhaustion great. He looked of a dull, leaden hue, reminding me of cholera collapse. His extremities were cold, his tongue clear and red, and he had great thirst. His skin, naturally dark, had on it several black-coloured mole-spots, chiefly on the neck and arms; the lips were not red, but of a dark purplish hue. All the other members of his family were fair and healthy. He had an attack of phlegmonous erysipelas in the left arm in 1860 , when two years old; tetanic symptoms set in ; free scarification gave relief, being followed by abundant purulent discharge and sloughing of the cellular tissue. He recovered, and had since enjoyed tolerably good health; but his mother said he had always been of a very sensitive nature, and highly emotional. The scar left where I made the incision was now of a dark coppery colour, and his shoulders were also striped with a band of the same dark hue, where they had been chafed by his braces and the basket which he carried as a baker's lad. The genitals were almost black, like those of a mulatto. The mole-spots were perfectly black, melanotic, varying in size from a dot to that of a shilling. His ankles were scarred by marks of the same dirty coppery colour, where his bouts had chafed the skin. His bowels were costive; but simple aperients acted well, the freces being healthy, with abundance of normal bile. His urine was acid, always in all respects healthy, without a trace of albumen. His abdomen was flat, and, on careful examination, gave no positive indications of disease. His sleep was tranquil, but his head swam when erect. The vomiting generally came on when he awoke and attempted to stand ; it was preceded by giddiness. Nothing but a little froth or phlegm was voided ordinarily, excepting what might have been swallowed immediately before. He improved a little, but lost flesh rapidly. He was able to take a little mutton occasionally; but beef-tea and milk were the staple articles of his food. There had been no pain in the loins, nor any sense of fulness or tender. ness. The tongue remained very clean and moist, the skin generally cold; but his pulse was about 80 , and small.

October 8th. Dr. Sutton kindly saw the case with me, and said all the abdominal organs seemed sound; but as to Addison's disease, he felt doubtful. The discoloration he considered too general, the wasting unusual, and the age of the patient younger than any case he had seen in marked disease of the suprarenal capsules. The patient was obliged to keep the recumbent posture ; his bowels became more constipated. The saline alkaline aperients suited best; the mineral acids did not agree. A little tincture of calumba, and then of bark, with carbonate of potash and sal volatile, sat best on the stomach.

November 6 th. He had improved for the last ten days. There had been no vomiting. The appetite improved; the bowels acted fairly; His complexion was better ; but the skin on the back looked coppery; and immediately above each knee there was a streaked space about an inch and a half wide, as if it had been brushed over with a purplish colour. This had been noticed during the last four or five days. He said he was not giddy, and wanted to go out.

March 3oth, 1872. He had been able to do a little work in the bake- 
house, but was soon exhausted. During the last week he had looked dull, and his lips were returning to their former bluish colour. He slept restlessly, starting much ; felt sick, and had vomited bile. Milk and beef-tea turned sour. He had grown much, his head swam, and he seemed confused on awaking. He sat moping over the fire, being very chilly. His pulse was miserably small.

April 2nd. He had kept his bed for some days, and appeared very weak, gasping often, without appetite. The skin was cold and pale, without fresh spots. I was hastily summoned in the afternoon, and found that he had broken out into a cold clammy sweat; gasping for breath, with a vacant fixed stare ; and had expired, just before my arrival, without a groan or movement.

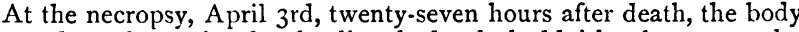
was pale and emaciated; the lips had a dark bluish, almost purple, colour, but not the interior of the mouth. The skin was generally rough, and of a bronzed tint, particularly over the genitals. The cicatrix in the arm was of a dark brown colour; and over his shoulders and ankles the skin was of the same dark coppery tint. The abdomen was flat. Not a trace of disease was observable, except some enlarged mesenteric glands; and in these there was no scrofulous deposit, merely hypertrophy. The kidneys were healthy. The suprarenal capsules were removed with great difficulty, being firmly bound down by dense cellular tissue. They were both considerably enlarged, hard, cartilaginous, with calcareous deposit in parts. The right was triangular, about half or three-fourths of an inch in thickness and an inch and a half long -very red externally, and covered with strong adhesive tissue. On being cut into, it exhibited several partitions filled by lardaceous, cheesy, semipurulent matter. The left was crescentic in shape ; being longer, but of the same dense gristly texture, and with similar contents. On April Ioth, I showed the right capsule to Drs. Sutton, Ramskill, and Hughlings Jackson, who all agreed that the specimen was one of well marked Addison's disease. Dr. Sutton said there were present the two stages - the recent whitish waxy semifibrous tissue; and the more advanced yellow cheesy calcareous deposit. Yellow points could be seen in different parts of the surface, which on section showed the same characteristics. The heart was flabby, with fluid blood in its cavities; there was no effusion in any of the serous cavities. In each lung, about the centre, was felt a hard cretaceous puckered body, as large as a bean, which seemed like a shrivelled tubercle; but not a trace of a tubercle could be discovered in any other part of either lung. Three or four bodies of the size and flat shape of melon-seeds were seen lying on the lumbar vertebræ under the peritoneum, which could be moved readily, as if floating under it. They were quite black, like flakes of melanotic pigment moulded into oval bodies, resembling small glands.

REMARKS. - The above case is of great interest, as it seems to me to confirm the English view of the pathology of Addison's disease, much doubted by the German school. It occurred in a young subject, and proved fatal from its intrinsic intensity, before the constitution was broken down by other concomitant disease. The only organic change observable in this case was enlarged suprarenal capsules; their natural structure being completely changed into dense cartilaginous tissue, divided into compartments, some filled with soft lardaceous matter, others with materials of various consistency, from semipurulent to rough calcareous deposit. The mesenteric glands were also enlarged, as commonly found in abdominal diseases of childhood; but there was no specific change in their structure. The distressing symptoms seem in the present case to have been due to the slow and steady progress ing disorganisation of the suprarenal capsules. No other complication was found ; in fact, the other organs of the body might have been pronounced perfectly healthy. The remarkably small pulse, exhaustion, chilliness, vomiting, constipation, acidity, and indigestion, have been referred to irritation of the solar plexus; and the dense character of the cellular tissue, in which the branches going to the suprarenal capsules were imbedded, the result of chronic inflammatory action, seems to confirm this opinion. Much stress has been laid upon the amount and character of the discoloration of the skin. It appears to me that we are in the dark as to the cause of this unusual pigmentation; at any rate, we know no definite rules or principles upon which deposit of the colouring matter of the blood takes place. We may have much or little, and we cannot tell why the tint may vary in all parts ; but those portions of the skin which have been abraded, chafed, or irritated, by friction, are most darkly marked, and especially the genitals. The startlings, semi-convulsive twitchings of the extremities in this case, especially during sleep, show that the spinal system of nerves is affected ; but, as Dr. H. M. Tuckwell has well observed, in his able paper in the St. Bartholomew's Hospital Reports ( 1871), "The more decided cerebrospinal symptoms are, as a rule, later manifestations in the disease, and seem to succeed to the more strictly sympathetic troubles." Again, "The neurosis and the pigmentation are explained by a long-continued irritation of the sympathetic nerve at its great centre." I would refer all who are interested in this subject to this valuable contribution to science, as well as to Dr. Greenhow's exhaustive treatise in the Transactions of the Pathological Society (1866). "The result of these labours was", Dr. Tuckwell observes, "to show that there exists a definite relation between a certain train of constitutional symptoms, attended by discoloration of the skin, and one particular organic lesion of the suprarenal capsules ; and further, that the careful observation of these symptoms will lead to the diagnosis of the presence or absence of this particular lesion, with as much certainty as can be attained in the diagnosis of any other organic lesion."

\section{A CASE OF FRACTURE OF THE SPINE.}

By GEORGE ALEXANDER GLOAG, L.K.Q.C.P.

Greenivay, aged about 50, by occupation a cab-driver, first came under my notice on A pril 3oth, 1872. He was suffering from the effects of a fall he had received a day or two previously. He stated that, while in the act of climbing to his box-seat, the horse became restless, and moved suddenly forward, throwing him violently to the ground. $\mathrm{He}$ found himself unable to walk, and was removed to his home in a cab. When I first saw him, he complained of some pain across the loins, extending down the back of the thighs and legs, and of having been severely shaken by the fall. There were no apparent signs of fracture ; he had perfect use of his limbs, and did not complain of tenderness or pressure in any particular part. His pulse was of average frequency, and normal in character. His most urgent symptom was a severe cough, from which he had suffered for a considerable period. The bowels being costive, I ordered him some purgative medicine and prescribed expectorants. On my next visit, he described himself as being much better; the pains were not so severe; his cough was soft and less urgent. Nothing occurred during the next week or ten days to retard his apparent progress towards recovery. In about a fortnight from the time the accident occurred, he felt well enough to walk up and see me, and to take moderate exercise in the open air. He continued to visit me every few days; his general health was good; all pains had left him, and the only inconvenience of which he complained was muscular stiffness. On June $20 t h$, he sent a message requesting me to visit him. On my arrival, I found him in bed. He complained of numbness in the legs and inability to walk. I found, on examination, that the lower half of the body was partially paralysed. He could move his legs, but was unable to draw them up without the assistance of his hands. Sensation was impaired in them; pricking or pinching the skin gave little pain; still he was able to distinguish what part of the thigh, leg, or foot was touched by the hand without the aid of sight. The paralysis of motion became complete, sensation diminished daily, and urine passed constantly without his knowledge.

On July 2nd, he was removed into the Bristol Royal Infirmary. Soon after his admission, he began to complain of numbness in his arms, then loss of power in the upper extremities. His breath became short, mucus accumulated in the bronchial tubes, which he was unable to cough up, and he died rather suddenly on July 6 th.

By the courtesy of Dr. Shingleton Smith, I am enabled to give the result of the post mortem examination. The three lower lumbar vertebræ were fractured transversely through the bodies, the transverse processes were uninjured, and there was no displacement. The cord and its membranes appeared uninjured. Some congestion of the membranes was found, but no blood or lymph had been effused, and there was no manifest softening. No change visible to the naked eye could be distinguished in the cord.

The history of this case furnishes some points of considerable interest. It is remarkable, considering the nature of the injury, that complete paraplegia was not the immediate result, and that the patient was able to walk without pain or difficilty soon after receiving it; and it is strange that no positive cause could be discovered after death to account for the paralysis which set in secondarily in the lower limbs, and gradually involved the upper extremities. It appears probable that local myelitis was the result of the injury, and the cause of the paraplegia, and that some minute change in the nerve-tissue rapidly extended from the lumbar to the cervical region, paralysing the muscles of respiration. I am inclined to think that, if this patient had remained in bed for four or six weeks after the accident, he would have made a good recovery. A long period of perfect rest seems to be of the utmost importance in spinal injuries. 